\title{
Analysis of soil fertility and mapping using geostatistical information system
}

\author{
Nazia Tahir ${ }^{1}$, Mohammad Jamal Khan ${ }^{1}$, Muhammad Ayaz ${ }^{2 *}$, \\ Muhammad $\mathrm{Ali}^{3}$, Ambreen Fatima ${ }^{4}$, Salman Ali $^{1}$ and Bibi Ayesha ${ }^{5}$ \\ 1. Department of Soil \& Environmental Sciences, University of Agriculture Peshawar-Pakistan \\ 2. College of Environment and Resources, Northwest A\&F University Yangling-712100 Shaanxi-China \\ 3. College of Horticulture, Northwest A\&F University Yangling-712100 Shaanxi-China \\ 4. Department of Irrigation and Drainage, University of Agriculture, Faisalabad-Pakistan \\ 5. Department of Environmental Sciences, Northern University of science and Technology, Nowshera-Pakistan \\ *Corresponding author's email: muhammadayaz111@aup.edu.pk \\ Citation \\ Nazia Tahir, Mohammad Jamal Khan, Muhammad Ayaz, Muhammad Ali, Ambreen Fatima, Salman Ali and Bibi \\ Ayesha. Analysis of soil fertility and mapping using geostatistical information system. Pure and Applied Biology. \\ Vol. 5, Issue 3, pp446-452. http://dx.doi.org/10.19045/bspab.2016.50057
}

Received: 18/02/2016

Revised: 06/05/2016

Accepted: $15 / 05 / 2016$

Online First: 28/05/2016

\section{Abstract}

Physico- chemical characterization of an agriculturally important soil and its fertility mapping was conducted by collecting 72 soil samples at two depths $(0-15$ and $15-30 \mathrm{~cm})$ from the Research Farm of Amir Muhammad Khan Campus, The University of Agriculture, Peshawar-Pakistan. These samples were collected at grid pattern with $100 \mathrm{~m}$ distances. The results indicated that all samples collected from the area were the total nitrogen content ranged from marginal to adequate level in some samples, ranges from deficient in $9.72 \%$, marginal in $33.33 \%$ and $56.95 \%$ sufficient nitrogen in the surface while in subsurface it was deficient $54.17 \%$, marginal in $30.83 \%$ and 15 $\%$ sufficient. The AB-DTPA extractable phosphorus was deficient in $97 \%$ surface and $100 \%$ subsurface soils while potassium was marginal to adequate levels in all samples with mean value of $150 \mathrm{mg} \mathrm{kg}^{-1}$. The surface soil sample was in adequate to the level of $58.33 \%$ and subsurface it range from $86.11 \%$ respectively. After analyzing the data though geostatistical techniques and GIS applications, fertility maps were developed though Kriging that delineated the status of soil properties at every sampled and non-sampled locations that could be used during planning for fertility management. Spatial trend and semivariogram were designed and spatial distribution of soil fertility status was further quantified and visualized. The kriging were used with three semivariogram models (circular, spherical and exponential). Mean Prediction Errors (MPE), Mean Standardized Prediction Errors (MSPE) and Root-Mean-Square Standardized Prediction Errors (RMSSPE) were used to evaluate the models. The results showed that the best model to generate soil fertility map was Kriging with all the three models on the best fitting formula, semivariogram model (MPE and MSPE close to 0, and RMSSPE close to 1).

Key words: Soil; Fertility; Kriging; GIS; MPE; MSPE; RMSSPE

Introduction

Soil fertility is the ability of soil to serve plant nutrients. It is used in a broad sense to cover any soil property that influence plants growth. Soil fertility and nutrient management influences plant growth 
livelihood, food security and vegetable production are influence by soil fertility and nutrient managements. Soils are variables inherently [1]. Soil variability is due to the product of soil forming factors which are operating and interacting over large distance and are modified and changes by other processes, that operate more frequently or more locally. The crop production is increased by different ways, however to access the macro and micro nutrient which are essential for the crop growth. On the basis of fertility status of soil and profitability, the fertilizer recommendation can be made. The fact that largest source of organic matter is crop residue but un-fortunately, in Pakistan and many other developed countries, negligible amount of crop residue is left in field after crop harvest especially of wheat and rice. The crop residue is either used to feed animals, to make papers or use as a fuel [1].

The impact of organic farming on soil physicchemical properties evaluated nutritional status of soils [2]. Data pertaining to Nitrogen showed that $51.79 \%, 28.57 \%, 16.07 \%$ soils were high, medium and low respectively. AB-DTPA extractable Phosphorus was adequate in $73.21 \%$ soil samples while 19.64 $\%$ were marginal and only $7.14 \%$ low in soil P. AB-DTPA extractable Potassium aried from 20.08 to $201.08 \mathrm{mg} \mathrm{kg}^{-1}$ soil but only $8.93 \%$ soil samples were deficient, while $50.0 \%$ and $41.07 \%$ of soil samples were adequate and marginal, research conducted by Raza and Sarir [2].

The field and laboratory investigations to study the spatial variability of plants nutrients under different cropping systems in soils of Peshawar district. 88 soil samples were collected from different areas of Peshawar at two depths $(0-15$ and $15-45 \mathrm{~cm})$ with known geo-position, result was similar with Rashid and Bhatti [3].

Keep in view the importance of fertility status and mapping (spatial variability), the present piece of research was undertaken to study the spatial distributions and fertility of the soil and prepare maps by using geo-statistical tool. To analyze fertility status of Amir Mohammad Khan Campus, The University of Agriculture Peshawar-Pakistan. Mapping of soils for macronutrient and analyze the fertility status for better fertilizer management.

\section{Materials and methods Total nitrogen}

Total nitrogen was determined by Kjeldhal method as described by Bremner [4]. The distillate of $65 \mathrm{~mL}$ was analysed for ammonium by a titration against $0.05 \mathrm{~N}$ $\mathrm{HCl}$. One blank reading that include $20 \mathrm{~mL}$ distilled water instead of sample was run from time to time in order to check any contamination of Kjeldhal apparatus and reagents

Total nitrogen $(\%)=\frac{(\text { Sample }- \text { Blank }) * 0.005 * 0.014 * 100 * 100}{\text { Wt. of soil } * 20}$

\section{AB-DTPA Extractable Phosphorous}

AB-DTPA extractable phosphorous content in soil samples was determined by extracting it in soil solution as described by Sultan-pour [5].

Absorption curve were developed on spectrophotometer for $0,2,4,6,8$ and $10 \mathrm{ug}$ $\mathrm{Pm}^{-1}$ standards which was then used for calculation of AB-DTPA extractable $\mathrm{P}$ in samples.

$A B-D T P A$ extractable P $(\mathrm{mg} / \mathrm{kg})=\frac{\text { Concentration } * \mathrm{ml} \text { of AB }- \text { DTPA }}{2 *(\text { Wt. of soil })}$

AB-DTPA Extractable Potassium

AB-DTPA Extractable Potassium was determined by flame Photometer in the solution by AB-DTPA determined [5]. The Standard solution of Potassium which were 20, 40, 60, 80 and $100 \mathrm{mg} / \mathrm{L}$ were tested, absorbance graph was developed before analysis of sample. One blank was also run in start on the machine in which sample was absent and AB-DTPA extract was only present.

$A B-$ DTPA extractable $K(\mathrm{mg} / \mathrm{kg})=\frac{(\mathrm{I} . \mathrm{R}-\text { blank }) \times \text { vol. } \times \text { D.F }(\text { If any })}{\text { Factor } \times \text { wt. of sample }}$ 
Geostatistics is a branch of applied statistics that highlighting on characterization of dependence in the measured variable or variables. It is used to model the spatial dependence of regionalization variables (s) or spatial variability of soil properties, to interpret spatial patterns and estimate the values of the attribute (s) at un sampled locations. All the statistical procedures such as Kriging and semivariogram analysis, used

Table 1. Shows maximum, minimum and mean values of major nutrients in surface and subsurface soil

\begin{tabular}{ccccccc}
\hline Plant nutrients & Depth $(\mathbf{c m})$ & Min & Max & Mean & S.D & CV\% \\
\hline \multirow{2}{*}{ Total nitrogen \% } & $0-15$ & 0.03 & 0.66 & 0.22 & 0.11 & 47.9 \\
\cline { 2 - 6 } & $15-30$ & 0.012 & 0.47 & 0.104 & 0.082 & 78.21 \\
\hline $\begin{array}{c}\text { AB-DTPA extractable } \\
\text { "P" mg/kg }\end{array}$ & $0-15$ & 0.90 & 5.7 & 1.73 & 0.73 & 42.26 \\
\cline { 2 - 7 } & $15-30$ & 0.70 & 2.0 & 1.22 & 0.34 & 28.02 \\
\hline $\begin{array}{c}\text { AB-DTPA extractable } \\
\text { "K" mg/kg }\end{array}$ & $0-15$ & 80.0 & 150.0 & 120.15 & 16.55 & 13.78 \\
\cline { 2 - 7 } & $15-30$ & 58.0 & 138.0 & 100.71 & 17.49 & 17.37 \\
\hline
\end{tabular}

Table 2. Shows major nutrients concentration in percentage

\begin{tabular}{lcccccc}
\hline & \multicolumn{2}{c}{ Total nitrogen \% } & $\begin{array}{c}\text { AB-DTPA extractable "P" } \\
\mathbf{m g} / \mathbf{k g}\end{array}$ & \multicolumn{2}{c}{$\begin{array}{c}\text { AB-DTPA extractable "K" } \\
\mathbf{~ m g / k g}\end{array}$} \\
\cline { 2 - 7 } Depths (cm) & $0-15$ & $15-30$ & $0-15$ & $15-30$ & $0-15$ & $15-30$ \\
\hline $\begin{array}{l}\text { Samples } \\
\text { deficient }\end{array}$ & 9.72 & 54.167 & 97.22 & 100 & -- & -- \\
$\begin{array}{l}\text { Samples } \\
\text { Marginal }\end{array}$ & 33.33 & 30.833 & 2.78 & -- & 58.33 & 58.33 \\
$\begin{array}{l}\text { Samples } \\
\text { Adequate }\end{array}$ & 56.95 & 15 & -- & -- & 41.67 & 41.67 \\
\hline
\end{tabular}

\section{Results and discussions}

Total nitrogen

Total nitrogen in surface soil ranged from $0.03 \%$ to $0.66 \%$. Total nitrogen was marginal in $33.33 \%$ samples and adequate in $56.9 \%$ samples in surface soil, while it was marginal in $30.833 \%$ samples and deficient in $54.16 \%$ in sub surface soil (table 2). The maximum value of $0.1049 \%$ and minimum value of $0.0120 \%$ in sub surface soil. for and estimation and analysis of spatially dependent variables were collectively known as "geostatistics" [6,7].

The soil macronutrient was analyse through Semivariogram Analysis and Punctual kriging. Data sets were scrutinised with different software packages. Maps were produced with GIS software ArcGIS 9.1 and its extension of Spatial Analyst. 
AB-DTPA extractable phosphorous ranged from $0.90 \mathrm{mg} / \mathrm{kg}$ to $5.7000 \mathrm{mg} / \mathrm{kg}$ in surface soil. AB-DTPA extractable phosphorous was marginal in $2.78 \%$ samples while it was deficient in $97.2 \%$ samples in surface soil. The soil showed a minimum value of $0.70 \mathrm{mg} / \mathrm{kg}$ and maximum value of $2.0 \mathrm{mg} / \mathrm{kg}$ in sub-surface soil. AB-DTPA extractable P was deficient in $100 \%$ samples in sub surface soil. Coefficient of variation was 42.26 in surface soil and it was 28.02 in sub surface, showed a wide range of variations in samples in both the surfaces, as shown in table 4. The results were similar to that of Raza and Sarir [2]. Generally the extracted phosphorous increased with increased $\mathrm{P}$ sorption under more surface area. Borrero studied the properties of $\mathrm{CaCO}_{3}$ and phosphate sorption of 36 calcareous soil samples in Mediterranean, part of Spain [9]. They concluded that $\mathrm{CaCO}_{3}$, because of its low surface area and low sorption capacity ,did not influence sorption markedly. Other soil components of calcareous soils, such as $\mathrm{Fe}$ oxides or silicate clay appear to be quantitatively more important, at least for sorption at low $\mathrm{P}$ equilibrium concentration. Iron oxides were the most active sorbents [10]. However long term sorption was affected by calcium carbonate content; Fe oxide seemed to contribute little to that process.

\section{AB-DTPA extractable potassium}

AB-DTPA extractable potassium ranged from 80.0 to $150.0 \mathrm{mg} / \mathrm{kg}$ in the surface soil while it ranged from a minimum of 58.0 $\mathrm{mg} / \mathrm{kg}$ to a maximum of $138.0 \mathrm{mg} /$ in sub surface. Standard deviation value was 16.6 in surface soil and 17.49 in sub surface soil. This showed great variation in values of samples. Coefficient of variance was higher in sub surface soil than surface soil. There was no deficiency of potassium in surface as well as sub surface soil. AB-DTPA extractable $\mathrm{K}$ was found adequate in
$41.67 \%$ samples in surface soil, while it was marginal in $58.33 \%$ samples in sub surface soil ,as shown in Table. These results were similar to the report of Rashid and Bhatti [3]. The two primary soil minerals, the micas and feldspars (orthoclase) form bulk of soil $\mathrm{K}$ reserves [11]. The sand fraction of the alluvial soils of Pakistan are mainly composed of quartz; feldspars and biotite mica. The granite and granodiorite derived soils have lesser mica and greater Ca-feldspar and chlorite in sand. The silt fractions are mainly composed of quartz, mica and chlorite. The moderately weathered silt has lower biotite than muscovite The less weathered alluvial soils contain the highest $\mathrm{K}$ both in sand and silt. The soils derived from shale, sandstone and limestone have the lowest extractable $\mathrm{K}$. The granite and granodiorite derived soils contain an intermediate amount of extractable K [12].

\section{Soil spatial variability result of macro nutrient.}

Semivariogram analysis of the data on the macro nutrient in the surface as well as subsurface of soil (Table 3) showed that total $\mathrm{N}$ content in both the depths showed random distribution and Exponential model in both depths. The nugget-sill-ratio was above $>75 \%$ in both the depths showed a weak spatial dependence, respectively (Figure1 to 2). The Phosphorous content of both the depths was described by Circular models in the surface and Exponential model in the subsurface, the surface soil had a very poor structure while it had a moderate spatial structure in the subsurface soil with an nugget-sill-ratio is in between $25-75 \%$ in both the depths (Figure 3 to 4 ). The potash content of the soil in both the depths was described by a Circular model with nuggetsill-ratio \% value of 0.67 in surface and 0.62 in the subsurface showing moderate spatial structure (Figure 5, 6). 
Table 3. Shows parameters of semivariogram models for major nutrients $(\mathbf{N}, \mathbf{P}, \mathrm{K})$ in surface and subsurface soil

\begin{tabular}{lcccccc}
\hline & \multicolumn{2}{c}{ Total nitrogen \% } & \multicolumn{2}{c}{$\begin{array}{c}\text { AB-DTPA extractable "P" } \\
\mathbf{~ m g / k g}\end{array}$} & \multicolumn{2}{c}{$\begin{array}{c}\text { AB-DTPA extractable "K" } \\
\mathbf{~ m g / k g}\end{array}$} \\
\cline { 2 - 7 } Depths $(\mathbf{c m})$ & $0-15$ & $15-30$ & $0-15$ & $15-30$ & $0-15$ & $15-30$ \\
\hline $\begin{array}{l}\text { Nugget } \\
\text { nugget-sill- }\end{array}$ & 0.0104 & 0.00658 & 0.2510 & 0.07641 & 227.7800 & 226.57 \\
ratio \% & 0.87 & 0.88 & 0.34 & 0.61 & 0.67 & 0.62 \\
MPE & 0.00014 & -0.00110 & -0.00445 & 0.00056 & 0.01843 & -0.03722 \\
MSPE & 0.00103 & -0.0122 & -0.00112 & 0.00206 & 0.00018 & -0.0020 \\
RMSSPE & 0.01500 & 1.00900 & 1.14700 & 0.99360 & 1.00700 & 0.99930 \\
Model & Exponential & Exponential & Circular & Exponential & Circular & Circular \\
\hline
\end{tabular}

\section{Mapping of soil macro and micro} nutrients

Map of Total nitrogen content of surface soil (Fig 1 and 1b) showed that there is irregular trend with low nitrogen content north-west part and south-east part had higher nitrogen content. However the same trend was also found in subsurface with an increasing trend from south-west to south-west direction. Similarly, phosphorus contents in both the depths were lower than the permissible limits. As regards spatial patterns, southern part had lower $\mathrm{P}$ contents than the other areas. Hence total P content was low in both surface and sub-surface soils (Fig 2 and 2b). Maps of potash contents of both the depths (Fig 3 and 3b) showed that almost all area had higher potassium content in both the depths. However south eastern parts in surface and sub-surface soil have higher K content.

Table 4. Shows AB-DTPA for $P$ and $K$

\begin{tabular}{lllll}
\hline $\begin{array}{l}\text { Measurement } \\
\text { and (unit) }\end{array}$ & Low & Marginal & Adequate & Reference \\
\hline O.M $(\%)$ & $<1.0$ & $1.0-2.0$ & $>2.0$ & Sultanpour, 1985;Sillianappa, 1982 \\
Total N $(\%)$ & $<0.1$ & $0.1-0.2$ & $>0.2$ & \\
$\begin{array}{l}\text { AB-DTPA } \\
\text { extractable P } \\
\text { (mg/kg) }\end{array}$ & $<4.0$ & $4.0-7.0$ & $>7.0$ & \\
$\begin{array}{l}\text { AB-DTPA } \\
\text { extractable K } \\
(\mathrm{mg} / \mathrm{kg})\end{array}$ & $<60$ & $60-120$ & $>120$ & Sultanpour,1985;Tendon,1993 \\
\hline
\end{tabular}


Tahir et al.

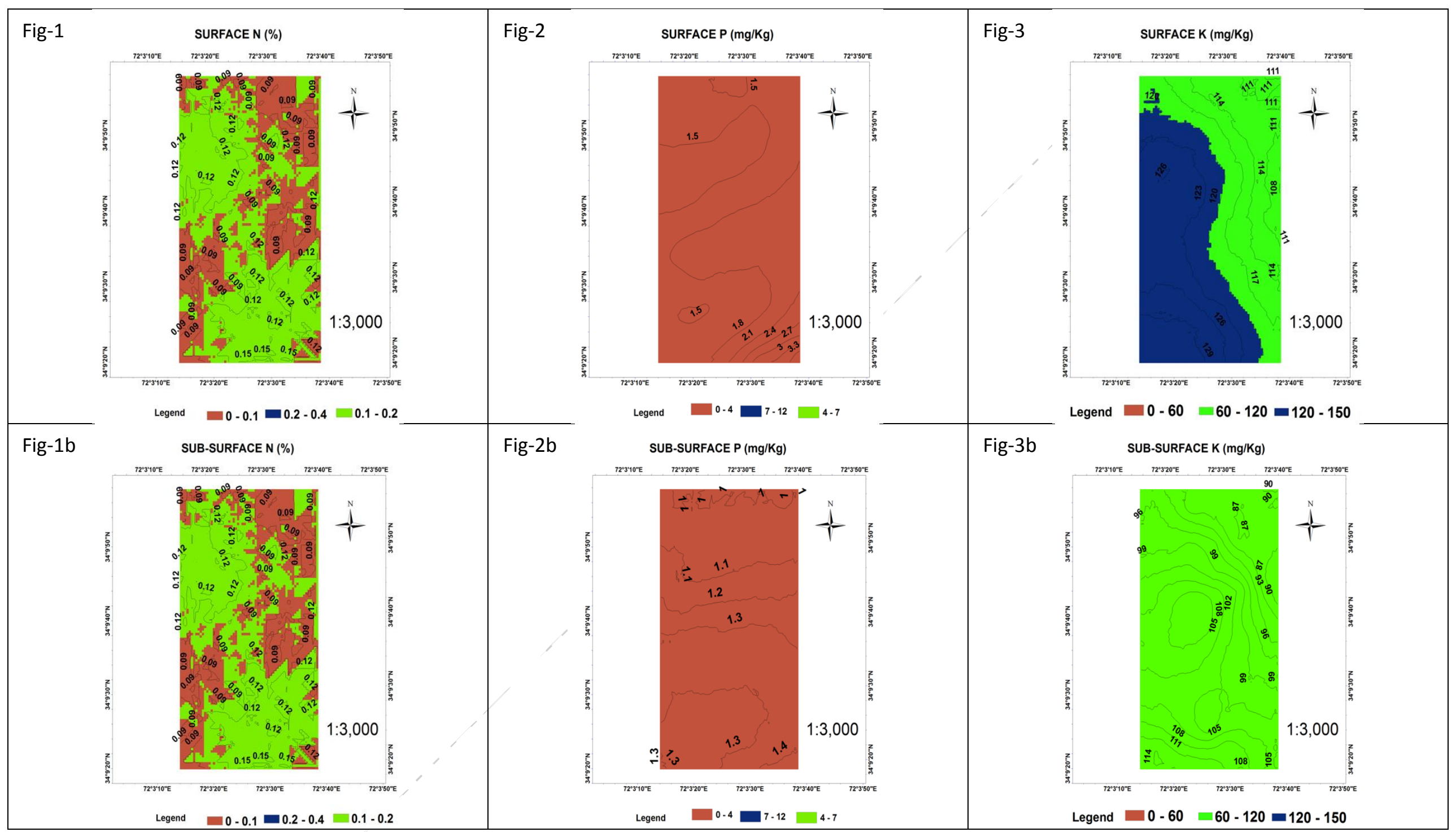




\section{Authors' contributions}

Conceived and designed the experiments: MJ Khan, Performed the experiments: $\mathrm{N}$ Tahir, Analyzed the data: M Ali, Contributed reagents/materials/analysis tools: B Ayesha \& A Fatima, Wrote the paper: M Ayaz \& S Ali.

\section{References}

1. Kauser MA, Rashid A \& KS Memon (1996). Soil organic matter. In Soil Science (ed). N B F, Islamabad, Pak 235256.

2. Raza K \& Sarir MS (2007). Fertility evaluation of organic manure treated soils of Northern areas. M.S Hons thesis. Soil and Environmental Sciences, NWFP Agri. Univ. Pesh. Pakistan.

3. Rashid M \& Bhatti AU (2005). Spatial variability of major and micro nutrients deficiency in soils of Peshawar district, M.S Hon. Agriculture University Peshawar.

4. Bremner JM (1996). Nitrogen total In D.L. Sparks (ed). Methods of Soil Analysis Part 3. Amer Soc Agron 37: 1085-1022

5. Sultanpour PN (1985).Use of AB-DTPA soil test to evaluate elemental variability and toxicity. Commun Soil Sci Plant Anal 16:323-338

6. Issaks EH \& Srivastava RM (1989). An introduction to applied Geostatistics. Oxford Press New York, USA. Pp 561
7. Bhatti AU (2000). Geostatistical techniques and applications for managing degraded soil for sustainable production. Sci Vision 1:27-35

8. Grace PR, Ladd JN \& Skjemstad JO (1994). The effect of management practices on soil organic matter dynamics. In Soil Biota: Management in sustainable Farming System. (SIRO, Melbourne. pp.162-171

9. Borrero L, Lanatay J \& Borella F (1988). Reestudiando huesos: Nuevas consideraciones sobre sitios de Última Esperanza. Anales del Instituto de la Patagonia, Serie Ciencias Sociales 18:133-156

10. Steel RGD \& Torrie JH (1980). Principles and procedures of Statistics. A biometrical Approach McGraw-Hill, New York, N.Y.2 ${ }^{\text {nd }}$ ed. pp. 633.

11. Al-Rawi AA \& Mohammadi NHA (1979). The potassium supplying power of some Iraqi alluvial soils as related to mineralogical composition. Proc.14th Collog. International Potash Institute, Sevilla (Spain). pp: 205-211

12. Awan ZI, Arshad M \& Akhtar MS (1998). Potassium release characteristic of sand and silt in relation to soil parent material and weathering stage. PJSS 15(3-4):94-105. 